\title{
COPD and air travel: does hypoxia-altitude simulation testing predict in-flight respiratory symptoms?
}

\author{
Anne Edvardsen ${ }^{1,2}$, Morten Ryg ${ }^{1}$, Aina Akerø ${ }^{3}$, Carl Christian Christensen ${ }^{1}$ and \\ Ole H. Skjønsberg ${ }^{3,4}$
}

Affiliations: ${ }^{1}$ Dept of Respiratory Physiology, Glittreklinikken, Hakadal, ${ }^{2}$ Faculty of Medicine, University of Oslo, Oslo, ${ }^{3}$ Dept of Pulmonary Medicine, Oslo University Hospital, University of Oslo, Oslo, and ${ }^{4}$ Institute of Clinical Medicine, Faculty of Medicine, University of Oslo, Oslo, Norway.

Correspondence: A. Edvardsen, Dept of Respiratory Physiology, Glittreklinikken, 1485 Hakadal, Norway. E-mail: anne.edvardsenaglittreklinikken.no

ABSTRACT The reduced pressure in an aircraft cabin may cause significant hypoxaemia and respiratory symptoms in patients with chronic obstructive pulmonary disease (COPD). The current study evaluated whether there is a relationship between hypoxaemia obtained during hypoxia-altitude simulation testing (HAST), simulating an altitude of $2438 \mathrm{~m}$, and the reporting of respiratory symptoms during air travel.

82 patients with moderate to very severe COPD answered an air travel questionnaire. Arterial oxygen tensions during HAST $\left(\mathrm{PaO}_{2 \mathrm{HAST}}\right)$ in subjects with and without in-flight respiratory symptoms were compared. The same questionnaire was answered within 1 year after the HAST.

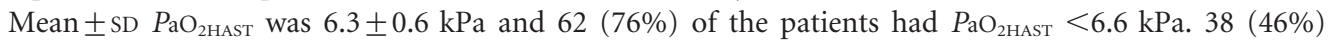
patients had experienced respiratory symptoms during air travel. There was no difference in $P a O_{2 \mathrm{HAST}}$ in those with and those without in-flight respiratory symptoms $(6.3 \pm 0.7 \mathrm{kPa}$ versus $6.3 \pm 0.6 \mathrm{kPa}$, respectively; $\mathrm{p}=0.926) .54(66 \%)$ patients travelled by air after the HAST, and patients equipped with supplemental oxygen $(n=23,43 \%)$ reported less respiratory symptoms when flying with than those without such treatment (four $(17 \%)$ versus $11(48 \%)$ patients; $\mathrm{p}=0.039)$.

In conclusion, no difference in $\mathrm{PaO}_{2 \mathrm{HAST}}$ was found between COPD patients with and without respiratory symptoms during air travel.

@ERSpublications

Hypoxia-altitude simulation testing does not predict in-flight respiratory symptoms in COPD patients http://ow.ly/nUCtF

For editorial comments see page 1175 .

Received: Oct 042012 | Accepted after revision: Dec 092012 | First published online: Dec 202012

Clinical trial: This study is registered at clinicaltrials.gov with identifier number NCT00896584.

Conflict of interest: None declared.

Copyright @ERS 2013 


\section{Introduction}

The low atmospheric pressure in an aircraft cabin may cause significant in-flight hypoxaemia in patients with lung disease [1-3]. In guidelines, recommendations and reviews dealing with air travel and lung disease, both respiratory symptoms and complications related to the negative effect of hypoxia on other organs, such as the heart, are addressed [1-3]. To ensure safe travel for patients with lung disease, pre-flight evaluation has focused on predicting in-flight hypoxaemia, and, if necessary, to supply the patients with oxygen during the flight.

Planned use of in-flight supplemental oxygen is recommended if in-flight arterial oxygen tension $\left(\mathrm{PaO}_{2}\right)$ is anticipated to fall below $6.6 \mathrm{kPa}[1,3]$. In-flight hypoxaemia has proven difficult to predict; neither sea-level arterial oxygen levels nor spirometric values alone seem to be reliable tools for this purpose [1]. In a recent study, we have shown that a combination of arterial oxygen saturation measured by pulse oximetry $\left(\mathrm{SpO}_{2}\right)$ at rest and $\mathrm{SpO}_{2}$ during exercise at sea level predicts in-flight hypoxaemia with high sensitivity and specificity in patients with chronic obstructive pulmonary disease (COPD) [4]. Some patients, however, are in need of more advanced pre-flight testing using a hypoxia-altitude simulation test (HAST), breathing a gas mixture with $15.1 \%$ oxygen, corresponding to an aircraft cabin altitude of 8000 feet $(2438 \mathrm{~m})$ [5-7].

In another study, we found that respiratory symptoms (dyspnoea or air hunger) during air travel were reported by $21 \%$ of patients with COPD, compared to $4 \%$ of healthy individuals [8]. Studies regarding the relationship between in-flight symptoms and hypoxaemia, however, are lacking. The effect of hypoxaemia on dyspnoea in patients with COPD is complex and poorly understood, and in general the sensation of dyspnoea seems to be more related to increase in ventilation than to decreased arterial oxygen tension per se [9-11]. The physiological and clinical basis for recommending pre-flight hypoxia testing has previously been questioned by NAEIJE [12].

The objective of the present observational study was to evaluate whether the patients reporting symptoms during air travel were those who developed severe hypoxaemia when tested with HAST. For this purpose, patients with moderate to very severe COPD were invited to answer a questionnaire regarding in-flight symptoms and the need of healthcare in the days following air travel. Subsequently, all patients performed HAST. Finally, the patients answered the same questionnaire within 1 year of the HAST, enabling us to study the consistency of symptoms in patients who did not use in-flight supplemental oxygen, and, in addition, the subjective effect of supplemental oxygen during the flight in patients receiving such treatment.

\section{Methods}

The current observational study was performed at a pulmonary rehabilitation hospital in Norway. Patients with moderate to very severe COPD [13] who were referred for pre-flight evaluation with HAST and who had travelled by air without supplemental oxygen within the past 2 years were consecutively invited to participate (fig. 1). The most frequent reasons for referral to pre-flight evaluation were previous air travel intolerance or severe and very severe COPD according to the Global Initiative for Chronic Obstructive Lung Disease (GOLD) spirometric classification [13]. The Regional Committee for Medical Research Ethics, Health Region East (Oslo, Norway) approved the study, and written informed consent was obtained from the participants. The study was registered at clinicaltrials.gov (NCT00896584).

\section{Subjects}

The study population comprised 82 patients, and had been studied previously (fig. 1)[4]. The inclusion criteria were moderate to very severe COPD [13] and air travel without supplemental oxygen performed within the past 2 years. Exclusion criteria were unstable angina, uncontrolled hypertension, uncontrolled arrhythmia or long-term oxygen treatment. 57 (70\%) of the participants had known comorbidities; the most frequent being systemic arterial hypertension, musculoskeletal disorders and ischaemic heart disease. All patients were in a stable phase of their COPD and comorbidities during both air travel and HAST, and they used their regular medication.

\section{Pulmonary function tests and blood gases}

Lung function tests included measurement of post-bronchodilator spirometry, diffusing capacity of the lung for carbon monoxide (DLCO) and total lung volumes (MasterScreen Pneumo; Jaeger-Toennis, Hoechberg, Germany). Reference values were based on equations from the European Steel and Coal Community [14].

After 10 min of rest in a sitting position, an arterial blood sample (PICO50; Radiometer, Copenhagen, Denmark) was drawn from a radial artery cannula. The sample was immediately analysed (ABL825 Flex; Radiometer). $\mathrm{SpO}_{2}$ was measured simultaneously (Nonin 2500 PalmSat; Nonin Medical Inc., Plymouth, MN, USA). 


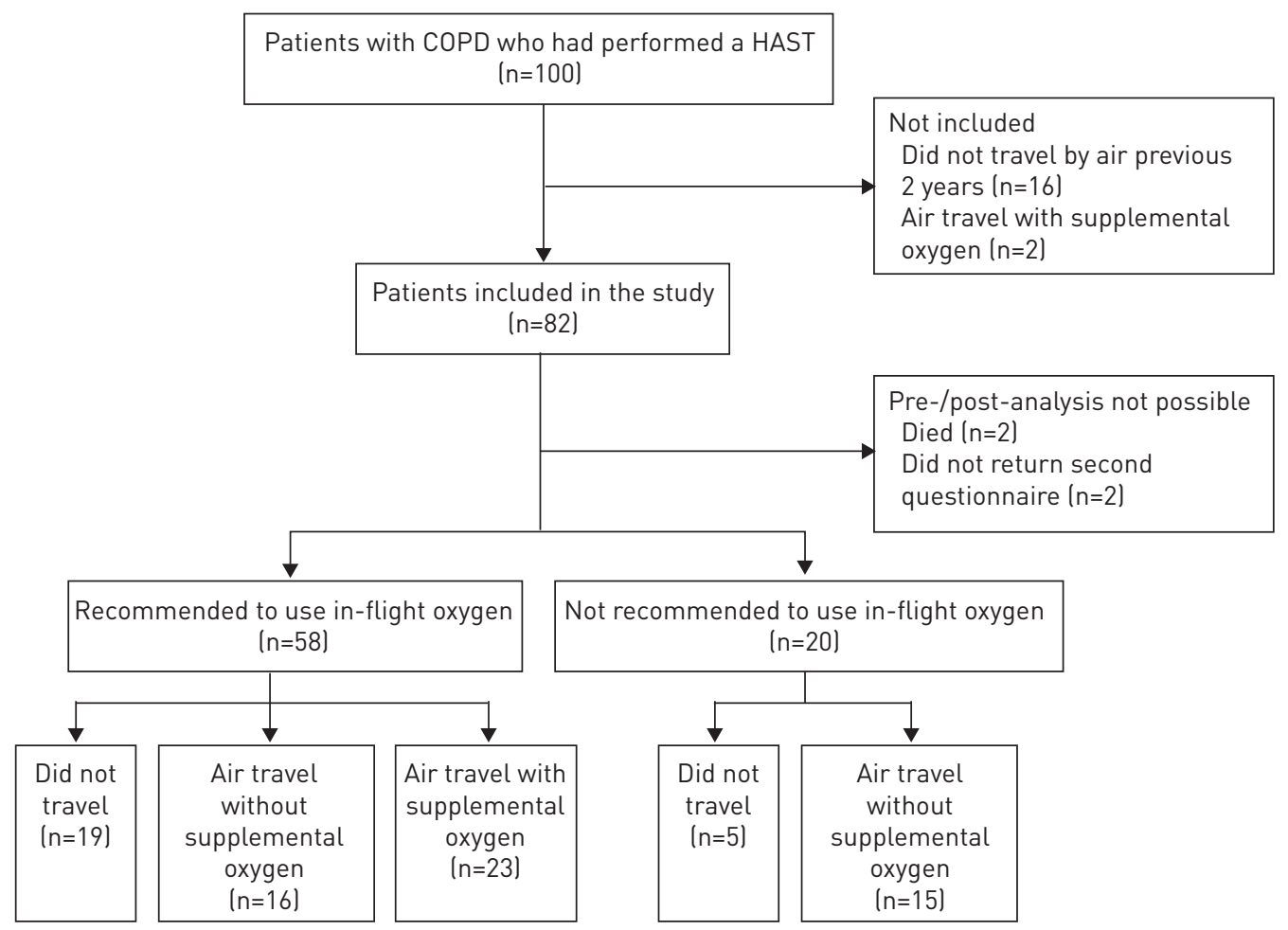

FIGURE 1 Flow chart describing patient selection. Patients with chronic obstructive pulmonary disease (COPD) evaluated by hypoxia-altitude simulation testing (HAST) who had travelled by air without supplemental oxygen and answered an air travel questionnaire were invited to participate. Reasons for not travelling were: not of interest $(n=11)$, worsening of the disease $(n=3)$, afraid of flying $(n=5)$ and other reasons $(n=5)$.

HAST

HAST was used to simulate a cabin pressure corresponding to an altitude of 8000 feet $(2438 \mathrm{~m}$ ) above sea level. During HAST the subjects breathed $15.1 \%$ oxygen $\left(15.1 \% \mathrm{O}_{2}, 84.9 \% \mathrm{~N}_{2}\right.$; Yara Praxair, Oslo, Norway) from a nondiffusing gas collection bag (170 L Douglas bag; Hans Rudolph Inc., Shawnee, KS, USA) and through a tight-fitting facemask (Mirage Full Face Mask; ResMed Corp, Poway, CA, USA). After 15 min, arterial blood samples were drawn from a radial arterial cannula and immediately analysed $[5,15]$. The $\mathrm{SpO}_{2}$ should be stable for $5 \mathrm{~min}$ before arterial blood sampling; otherwise the test was prolonged to $20 \mathrm{~min}$. ECG, $\mathrm{SpO}_{2}$ and symptoms (Borg CR-10 scale) [16] were continuously monitored. Patients with $\mathrm{PaO}_{2 \mathrm{HAST}}$ $<6.6 \mathrm{kPa}$ were recommended to use in-flight supplemental oxygen [1].

\section{Questionnaire}

All patients completed an air travel questionnaire [8] elucidating in-flight symptoms; dyspnoea or air hunger (hereafter defined as respiratory symptoms), dizziness, headache, chest pain, cough, fainting and palpitations experienced during flights undertaken within the past 2 years prior to the HAST. The patients also reported use of acute supplemental oxygen, and need of medical care after the air travel. In addition, all patients were asked to answer an identical air travel questionnaire within 6-12 months after the HAST.

\section{Statistics}

Descriptive data are presented as mean \pm SD, unless otherwise specified. Univariate analyses (independent samples t-test and Chi-squared test as appropriate) were used for the assessment of the relationship between respiratory symptoms and $\mathrm{PaO}_{2 \mathrm{HAST}}$. Univariate exploratory analyses were performed using McNemar's test, the Pearson Chisquared test or Fisher's exact test for categorical variables. A significance level of $5 \%$ was used. The $\kappa$-statistic was used to measure the test-retest reliability of the air travel questionnaire. To get an impression of statistical power, the present sample size would allow detection of a mean $\mathrm{PaO}_{2 \mathrm{HAST}}$ difference of $0.45 \mathrm{kPa}$ with a power of $80 \%$.

\section{Results}

\section{Subject characteristics}

Data from 82 patients with moderate to very severe COPD who had travelled by air within the last 2 years are presented in table 1. According to the GOLD classification of severity of airflow limitation [13] there were $19(23 \%), 49(60 \%)$ and $14(17 \%)$ patients with COPD grade 2, 3 and 4, respectively. 


\section{TABLE 1 Subject characteristics}

\begin{tabular}{|c|c|}
\hline Subjects $\mathrm{n}$ & 82 \\
\hline Sex male/female $n / n$ & $34 / 48$ \\
\hline Age years & $65 \pm 7$ \\
\hline BMI $\mathrm{kg} \cdot \mathrm{m}^{-2}$ & $24.9 \pm 4.8$ \\
\hline \multicolumn{2}{|l|}{ Lung function } \\
\hline FEV1 L & $1.0 \pm 0.4$ \\
\hline FEV $1 \%$ pred & $41 \pm 13$ \\
\hline FVC L & $2.4 \pm 0.8$ \\
\hline FVC \% pred & $75 \pm 21$ \\
\hline $\mathrm{FEV} 1 / F V C$ & $0.45 \pm 0.10$ \\
\hline DLCO $\mathrm{mmol} \cdot \mathrm{min}^{-1} \cdot \mathrm{kPa}^{-1}$ & $3.2 \pm 1.3$ \\
\hline DLco \% pred & $40 \pm 16$ \\
\hline RV L & $4.4 \pm 1.5$ \\
\hline RV \% pred & $198 \pm 64$ \\
\hline RV/TLC \% & $60.3 \pm 9.6$ \\
\hline RV/TLC $\%$ pred & $149 \pm 24$ \\
\hline \multicolumn{2}{|c|}{ Blood gases and pulse oximetry at sea level } \\
\hline $\mathrm{PaO}_{2} \mathrm{kPa}$ & $9.0 \pm 1.1$ \\
\hline $\mathrm{PaCO}_{2} \mathrm{kPa}$ & $5.1 \pm 0.6$ \\
\hline $\mathrm{SpO}_{2} \%$ & $93 \pm 3$ \\
\hline \multicolumn{2}{|c|}{ HAST blood gases and pulse oximetry } \\
\hline $\mathrm{PaO}_{2} \mathrm{kPa}$ & $6.3 \pm 0.6$ \\
\hline $\mathrm{PaCO}_{2} \mathrm{kPa}$ & $4.9 \pm 0.6$ \\
\hline $\mathrm{SpO}_{2} \%$ & $83 \pm 4$ \\
\hline
\end{tabular}

Data are presented as mean \pm SD, unless otherwise stated. BMI: body mass index; FEV1: forced expiratory volume in $1 \mathrm{~s} ; \%$ pred: \% predicted; FVC: forced vital capacity; DLCO: diffusing capacity of the lung for carbon monoxide; RV: residual volume; TLC: total lung capacity; $\mathrm{PaO}_{2}$ : arterial oxygen tension; $\mathrm{PaCO}_{2}$ : arterial carbon dioxide tension; $\mathrm{SpO}_{2}$ : arterial oxygen saturation measured by pulse oximetry; HAST: hypoxia-altitude simulation test.

\section{HAST results}

The mean $\mathrm{PaO}_{2 \mathrm{HAST}}$ was $6.3 \pm 0.6 \mathrm{kPa} .62(76 \%)$ patients had $\mathrm{PaO}_{2 \mathrm{HAST}}<6.6 \mathrm{kPa}$ and were recommended to use in-flight supplemental oxygen. Mean $P_{\mathrm{aCO}_{2 \mathrm{HAST}}}$ was $4.9 \pm 0.6 \mathrm{kPa}$ (table 1). There was a significant increase in dyspnoea score during HAST $(0.5$ to $1.3, \mathrm{p}<0.001)$. No difference in median dyspnoea score between those with (1, range 0-6) and those without (1, range $0-4.5)$ in-flight respiratory symptoms was observed $(\mathrm{p}=0.262)$. None of the patients had arrhythmias or signs of ischaemia in the ECG during HAST.

Air travel, symptoms and use of medical care

All patients had travelled by air without supplemental oxygen before referral to HAST. In the first questionnaire, respiratory symptoms were by far the most common and were experienced by 38 (46\%) patients.

FIGURE 2 Symptoms during air travel before pre-flight evaluation with the hypoxia-altitude simulation test. $\mathrm{n}=82$.

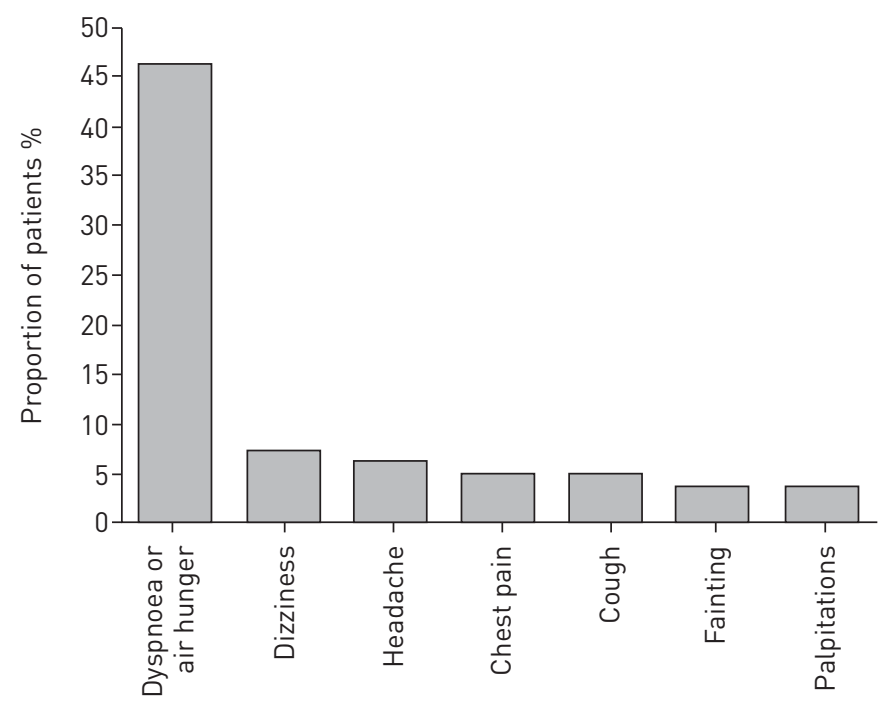




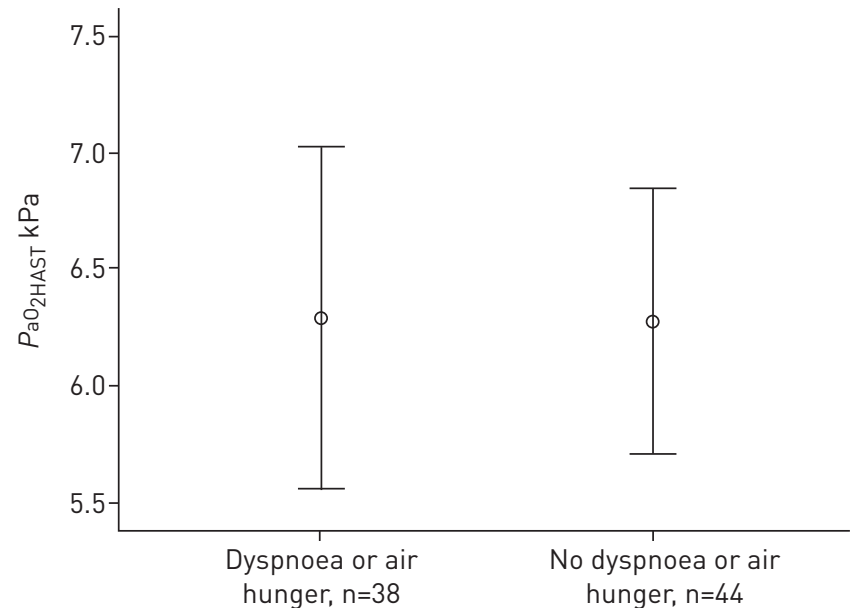

FIGURE 3 Dyspnoea or air hunger and arterial oxygen tension during hypoxia-altitude simulation testing $\left(\mathrm{PaO}_{2 \mathrm{HAST}}\right) . \mathrm{n}=82$.

Dizziness and headache were reported by six (7\%) and five (6\%) patients, respectively (fig. 2). Eight (10\%) patients had needed unscheduled acute oxygen treatment in the aircraft cabin; seven patients due to respiratory symptoms and one due to fainting. 14 (17\%) patients needed medical care within $48 \mathrm{~h}$ of arrival. Of these, mean $\mathrm{PaO}_{2 \mathrm{HAST}}$ was $6.0 \pm 0.6 \mathrm{kPa}$, and all had $\mathrm{PaO}_{2 \mathrm{HAST}}<6.6 \mathrm{kPa}$. Seven $(8 \%)$ of these patients were admitted to hospital and seven $(8 \%)$ patients received outpatient treatment. Those who did not require medical care had a mean $\mathrm{PaO}_{2 \mathrm{HAST}} 6.3 \pm 0.7 \mathrm{kPa}(\mathrm{p}=0.093)$.

\section{Association between in-flight respiratory symptoms and $\mathrm{PaO}_{2 H A S T}$}

There was no difference in $\mathrm{PaO}_{2 \mathrm{HAST}}$ between those with and those without in-flight respiratory symptoms $(6.3 \pm 0.7 \mathrm{kPa}$ versus $6.3 \pm 0.6 \mathrm{kPa} ; \mathrm{p}=0.926)$ (fig. 3$)$. There was a tendency towards more respiratory symptoms for patients with $P_{\mathrm{aO}} \mathrm{O}_{2 \mathrm{HAST}}$ below the median value $6.3 \mathrm{kPa}(54 \%)$ versus $\mathrm{PaO}_{2 \mathrm{HAST}}>6.3 \mathrm{kPa}(39 \%)$ $(\mathrm{p}=0.184)$. There was no association between $\mathrm{PaO}_{2 \mathrm{HAST}}$ and other in-flight symptoms.

\section{Second questionnaire}

$78(95 \%)$ of the 82 patients answered the second questionnaire within 12 months of the HAST (fig. 1). 54 $(66 \%)$ patients had travelled by air in the interval between the first and the second questionnaire. 31 of these patients did not use supplemental oxygen during any of the flights, and the prevalence of respiratory symptoms reported in the two questionnaires by these patients showed no significant difference (36\% and $45 \%$, respectively; $\mathrm{p}=0.453$ ) (fig. 4). For these patients there was good consistency in the reporting of respiratory symptoms; $24(77 \%)$ of the 31 patients gave identical answers in the first and the second questionnaire $(\kappa=0.54)$. Three $(10 \%)$ of the 31 patients who travelled without supplemental oxygen needed unscheduled acute oxygen treatment due to respiratory symptoms when travelling after HAST, a similar

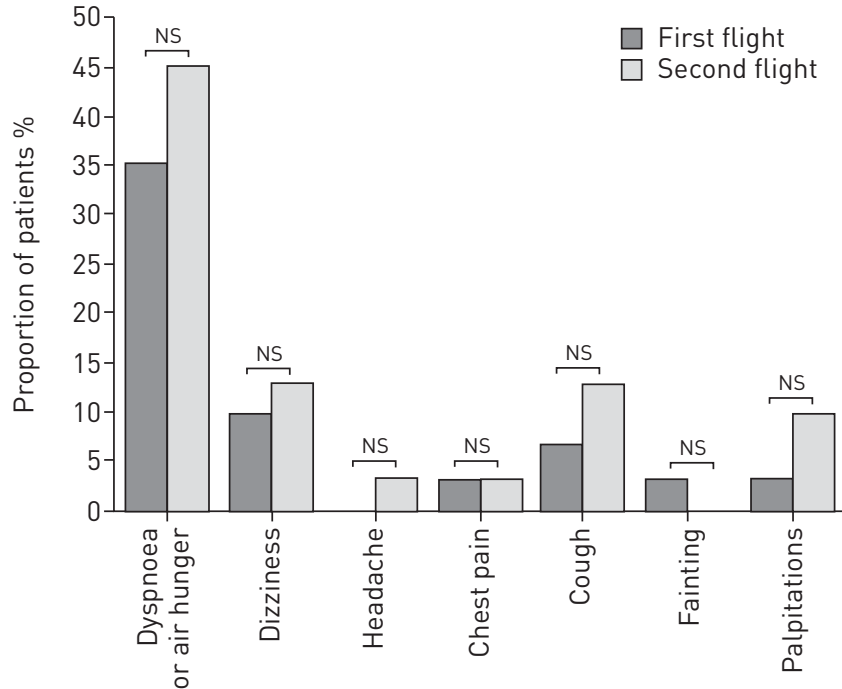

FIGURE 4 Symptoms during air travel for patients who flew without supplemental oxygen both the first and the second time. $\mathrm{n}=31$. Ns: not significant. 
FIGURE 5 Symptoms during air travel for patients who flew the first time without and the second time with supplemental oxygen. $n=23$. NS: not significant. ${ }^{\#}: \mathrm{p}=0.039$.

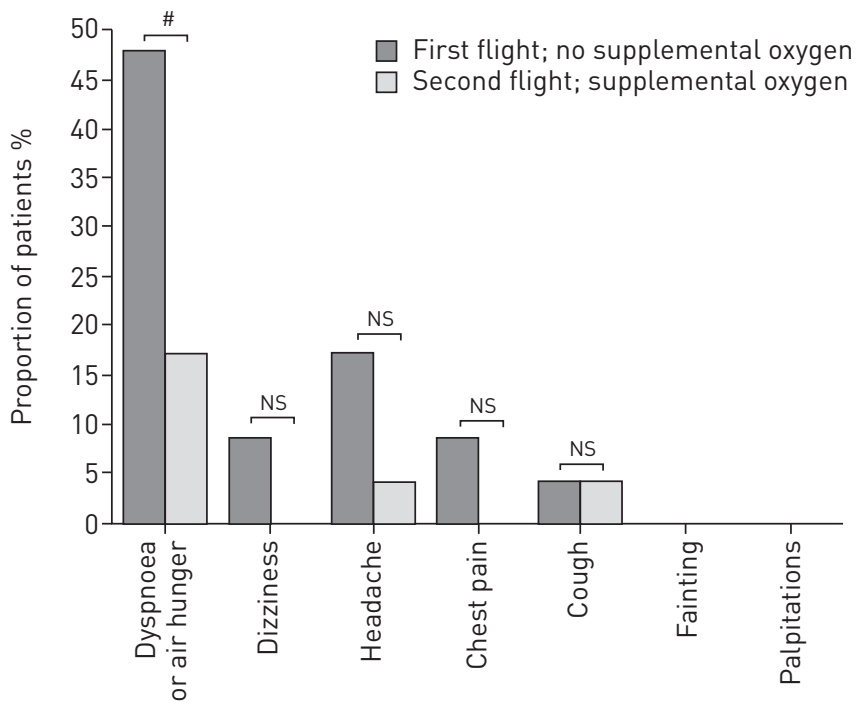

percentage as in the first questionnaire, and one (3\%) patient reported need of healthcare within $48 \mathrm{~h}$ after the flight, compared to $17 \%$ (14 out of 82 ) in the first questionnaire $(p=0.039)$.

\section{In-flight respiratory symptoms when using supplemental oxygen}

$23(43 \%)$ of the 54 patients used planned supplemental oxygen during their flight after HAST, and there was a significant decrease in the prevalence of respiratory symptoms when travelling with supplemental oxygen compared to travelling without oxygen treatment $(17 \%$ versus $48 \%)(p=0.039)$ (fig. 5). The 23 patients who used supplemental oxygen also had significantly lower prevalence of in-flight respiratory symptoms than the 31 patients who did not use such treatment $(17 \%$ versus $45 \%)(\mathrm{p}=0.032)$ (fig. 6).

\section{Discussion}

The aim of pre-flight assessment in patients with lung disease is to enhance air travel safety, with the identification of patients likely to develop severe in-flight hypoxaemia. The decreased oxygen saturation may exacerbate coexisting medical conditions, such as coronary heart disease, and may also be related to the development of respiratory distress during or after the flight $[1-3,11]$. Respiratory symptoms during air travel are reported by approximately one out of five patients with COPD $[8,17,18]$, and the development of severe hypoxaemia is well documented, both during real and simulated flights [1, 3, 15, 19-21]. The association between in-flight respiratory symptoms and hypoxaemia has, however, not been studied. In the current study, comprising patients with moderate to very severe COPD, we found no difference in $\mathrm{PaO}_{2}$ obtained during a simulated flight in those experiencing respiratory symptoms during air travel and those who did not. Somewhat contradictory to this finding, planned use of in-flight supplemental oxygen in patients with $\mathrm{PaO}_{2 \mathrm{HAST}}<6.6 \mathrm{kPa}$ resulted in a lower frequency of respiratory symptoms.

Almost $50 \%$ of the patients in the current study reported respiratory symptoms. This is considerably higher than in previous studies, which have reported $18-21 \%[8,17,18]$. The discrepancy may be explained by COPD severity and the fact that some of our patients were referred to HAST because of symptoms during previous flights. The $\kappa$-value when comparing respiratory symptoms reported by the patients who flew both times without supplemental oxygen was high, indicating an acceptable test-retest reliability. In accordance with our previous study [8], other symptoms like dizziness, fainting and headache were scarcely reported. This strengthens the finding of respiratory symptoms as a dominating concern during air travel for patients with COPD. The lack of association between respiratory symptoms and $\mathrm{PaO}_{2}$ during HAST is in agreement with observations at sea level, where dyspnoea in general is poorly correlated with blood gas abnormalities, both at rest and during exercise $[9,22]$. It has also been shown that patients with COPD may become severely hypoxaemic during air travel without having any symptoms [23]. Dyspnoea represents a variety of qualitatively distinct sensations and is the result of stimulation of a number of mechanoreceptors throughout the airways, lungs and chest wall, in addition to inadequate delivery of oxygen to peripheral muscles [9]. Other pathophysiological factors claimed to contribute to dyspnoea in patients with COPD are increased mechanical loading of inspiratory muscles in hyperinflated lungs [9] and also hypoxic effects on the cardiac pump and the pulmonary vasculature [24]. In addition, there seems to be a considerable variability between individuals in how these sensations are interpreted and to what extent they report 


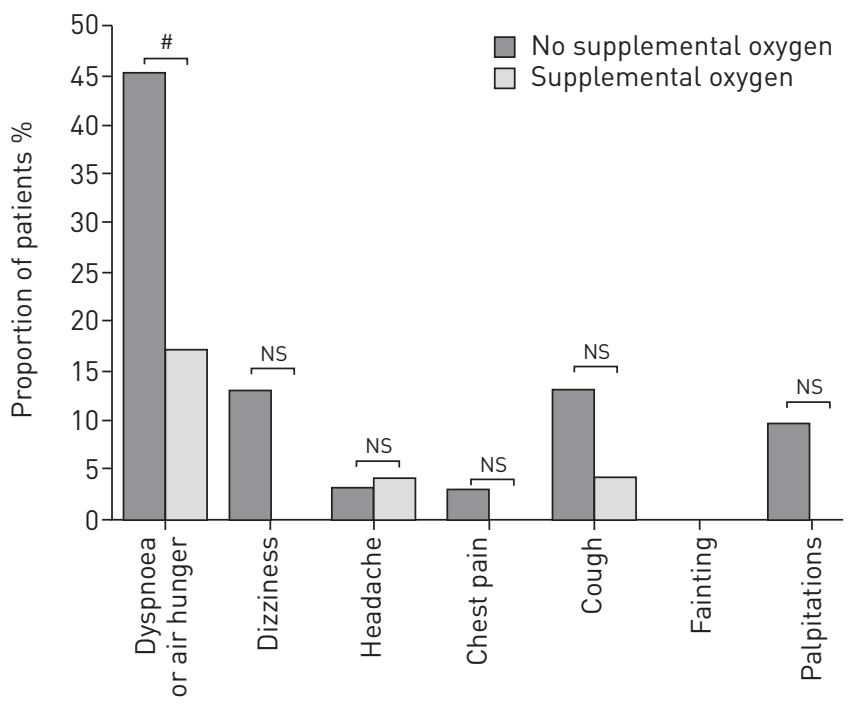

FIGURE 6 Symptoms during air travel for patients who flew the second time without $(\mathrm{n}=31)$ and with $(\mathrm{n}=23)$ supplemental oxygen. Ns: not significant. ${ }^{*}: \mathrm{p}=0.032$.

dyspnoea or respiratory distress [9]. The physiological compensation for acute altitude hypoxia is a nonlinear increase in ventilation, which may contribute to the feeling of dyspnoea [1, 10]. There is, however, a considerable individual variation with regard to the level of hypoxaemia needed to increase ventilation, ranging from $\mathrm{PaO}_{2} 6.7 \mathrm{kPa}$ to $8 \mathrm{kPa}$, before an appreciable increase in ventilation is observed [25]. Taken together, there seems to be a poor relationship between dyspnoea and the degree of hypoxaemia both at sea level and, as presented in the current study, during air travel.

In contrast to the lack of association between respiratory symptoms and HAST-induced hypoxaemia, the COPD patients experienced significantly less respiratory symptoms when flying with than without supplemental oxygen. This is in concordance with studies on COPD patients using supplemental oxygen during exercise $[26,27]$. It has been shown that supplemental oxygen may reverse the hyperventilatory response to hypobaric hypoxia in patients with COPD, thereby having a positive influence on the feeling of dyspnoea [28]. Supplemental oxygen may also cause beneficial haemodynamic changes [29]. It should be noted, however, that the effect of supplemental oxygen in the current study was not placebo controlled, and it has previously been shown that oxygen treatment is encumbered with a considerable placebo effect [30]. Therefore, randomised and placebo-controlled studies are needed to elucidate the effect of supplemental oxygen on in-flight dyspnoea.

Air travel is safe for most passengers with respiratory disease, but it is worth noting that respiratory-related medical problems are the third most reported cause of in-flight emergencies [1,17], and may cause medical flight diversions [1]. The current study indicates that pre-flight evaluation with HAST has no value for predicting in-flight respiratory symptoms. Relief of respiratory symptoms is not, however, the main reason for giving supplemental oxygen during air travel. Worsening of comorbidities such as cardiovascular disease, which is very common in the COPD population, is the most threatening consequence of severe hypoxaemia [1-3]. In addition, we recorded a high proportion of patients needing healthcare assistance after arrival. Whether this is related to the hypoxic exposure is not known. It should be noted that all but one of these patients had $\mathrm{PaO}_{2 \mathrm{HAST}}$ below the recommended limit for supplemental oxygen, and only one had used in-flight supplemental oxygen. Little information exists regarding medical events occurring after air travel [31] and, as requested in the British Thoracic Society recommendations, further studies designed to evaluate post-flight outcomes in patients with COPD are warranted [1].

The current study has some limitations. The authors have no data on the actual cabin pressure during the individual flights, which may vary between 6000 and 8000 feet [1]. This may possibly explain some of the variation in symptoms reported. In addition, worsening of the disease and recall bias in the time span between air travel and HAST may have influenced the results. Conversely, a prospective design where participants are asked to record in-flight respiratory distress may lead to increased symptom awareness, and thereby over-reporting of symptoms [8]. As shown in the second questionnaire, almost half of the patients with a $\mathrm{PaO}_{2 \mathrm{HAST}}<6.6 \mathrm{kPa}$ chose to fly without supplemental oxygen despite our recommendations. This may imply a selection bias with regard to the subjective effect of oxygen treatment on respiratory symptoms. In addition, the oxygen treatment was not placebo controlled. Thus, the positive effect of supplemental oxygen is encumbered with uncertainty. 
In conclusion, the current study comprising patients with moderate to very severe COPD showed no significant relationship between respiratory symptoms during air travel and the degree of hypoxaemia during a simulated flight.

\section{Acknowledgement}

Leiv Sandvik (Dept of Biostatistics and Epidemiology, Oslo University Hospital, Oslo, Norway) is gratefully acknowledged.

\section{References}

1 Ahmedzai S, Balfour-Lynn IM, Bewick T, et al. Managing passengers with stable respiratory disease planning air travel: British Thoracic Society recommendations. Thorax 2011; 66: i1-i30.

2 Aerospace Medical Association Medical Guidelines Task Force. Medical guidelines for airline travel, 2nd ed. Aviat Space Environ Med 2003; 74: Suppl. 5, A1-A19.

Silverman D, Gendreau M. Medical issues associated with commercial flights. Lancet 2009; 373: 2067-2077.

4 Edvardsen A, Akero A, Christensen CC, et al. Air travel and chronic obstructive pulmonary disease: a new algorithm for pre-flight evaluation. Thorax 2012; 67: 964-969.

5 Gong H Jr, Tashkin DP, Lee EY, et al. Hypoxia-altitude simulation test. Evaluation of patients with chronic airway obstruction. Am Rev Respir Dis 1984; 130: 980-986.

6 Mohr LC. The hypoxia altitude simulation test: an increasingly performed test for the evaluation of patients prior to air travel. Chest 2008; 133: 839-842.

7 Akero A, Christensen CC, Edvardsen A, et al. Pulse oximetry in the preflight evaluation of patients with chronic obstructive pulmonary disease. Aviat Space Environ Med 2008; 79: 518-524.

8 Edvardsen A, Akero A, Hardie JA, et al. High prevalence of respiratory symptoms during air travel in patients with COPD. Respir Med 2011; 105: 50-56.

9 Parshall MB, Schwartzstein RM, Adams L, et al. An official American Thoracic Society statement: update on the mechanisms, assessment, and management of dyspnea. Am J Respir Crit Care Med 2012; 185: 435-452.

10 West JB, Schoene RB, Milledge JS. High Altitude Medicine and Physiology. 4th Edn. London, Hodder Arnold, 2007.

11 Mohr LC. Hypoxia during air travel in adults with pulmonary disease. Am J Med Sci 2008; 335: 71-79.

12 Naeije RL. Preflight medical screening of patients. Eur Respir J 2000; 16: 197-199.

13 Global Initiative for Chronic Obstructive Lung Disease. The Global Strategy for the Diagnosis, Management and Prevention of COPD 2013. www.goldcopd.org/guidelines-global-strategy-for-diagnosis-management.html Date last accessed: August 18, 2013. Date last updated: February 2013.

14 Quanjer PH, Tammeling GJ, Cotes JE, et al. Lung volumes and forced ventilatory flows. Report Working Party "Standardization of Lung Function Tests", ECSC, Official Statement European Respiratory Society. Eur Respir J 1993; 6: Suppl. 16, 5-40.

15 Akero A, Edvardsen A, Christensen CC, et al. COPD and air travel: oxygen equipment and pre-flight titration of supplemental oxygen. Chest 2011; 140: 84-90.

16 Borg GA. Psychophysical bases of perceived exertion. Med Sci Sports Exerc 1982; 14: 377-381.

17 Coker RK, Shiner RJ, Partridge MR. Is air travel safe for those with lung disease? Eur Respir J 2007; 30: 1057-1063.

18 Dillard TA, Beninati WA, Berg BW. Air travel in patients with chronic obstructive pulmonary disease. Arch Intern Med 1991; 151: 1793-1795.

19 Christensen CC, Ryg M, Refvem OK, et al. Development of severe hypoxaemia in chronic obstructive pulmonary disease patients at 2,438 m (8,000 ft) altitude. Eur Respir J 2000; 15: 635-639.

20 Akero A, Christensen CC, Edvardsen A, et al. Hypoxaemia in chronic obstructive pulmonary disease patients during a commercial flight. Eur Respir J 2005; 25: 725-730.

21 Seccombe LM, Kelly PT, Wong CK, et al. Effect of simulated commercial flight on oxygenation in patients with interstitial lung disease and chronic obstructive pulmonary disease. Thorax 2004; 59: 966-970.

22 Mahler DA, O’Donnell DE. Dyspnea. Mechanisms, Measurement, and Management. 2nd Edn. Boca Raton, Taylor \& Francis Group, 2005.

23 Schwartz JS, Bencowitz HZ, Moser KM. Air travel hypoxemia with chronic obstructive pulmonary disease. Ann Intern Med 1984; 100: 473-477.

24 Mortazavi A, Eisenberg MJ, Langleben D, et al. Altitude-related hypoxia: risk assessment and management for passengers on commerical aircraft. Aviat Space Environ Med 2003; 74: 922-927.

25 West JB. Pulmonary Physiology and Pathophysiology. 2nd Edn. Baltimore, Lippincott Williams \& Wilkins, 2007.

26 Somfay A, Porszasz J, Lee SM, et al. Dose-response effect of oxygen on hyperinflation and exercise endurance in nonhypoxaemic COPD patients. Eur Respir J 2001; 18: 77-84.

27 O’Donnell DE, D'Arsigny C, Webb KA. Effects of hyperoxia on ventilatory limitation during exercise in advanced chronic obstructive pulmonary disease. Am J Respir Crit Care Med 2001; 163: 892-898.

28 Berg BW, Dillard TA, Rajagopal KR, et al. Oxygen supplementation during air travel in patients with chronic obstructive lung disease. Chest 1992; 101: 638-641.

29 Berg BW, Dillard TA, Derderian SS, et al. Hemodynamic effects of altitude exposure and oxygen administration in chronic obstructive pulmonary disease. Am J Med 1993; 94: 407-412.

30 Moore RP, Berlowitz DJ, Denehy L, et al. A randomised trial of domiciliary, ambulatory oxygen in patients with COPD and dyspnoea but without resting hypoxaemia. Thorax 2011; 66: 32-37.

31 Mattison ML, Zeidel M. Navigating the challenges of in-flight emergencies. JAMA 2011; 305: 2003-2004. 